\title{
Joint loads and muscle force distribution during classical and jazz pirouettes
}

\author{
MICHALINA BŁAŻKIEWICZ* \\ Józef Piłsudski University of Physical Education, Warsaw, Poland.
}

\begin{abstract}
Purpose: The objective of this study was to analyze the muscle force distribution and lower limb joint loading during two types of pirouettes and check which muscle in which pirouette generates the highest force and which joint is the most loaded. Methods: Skilled dancers $(n=16)$ performed single-turn pirouettes in jazz and classic styles. Kinematic and kinetic data were collected using the Vicon system and Kistler plates. The joint reaction forces and muscle forces were calculated using a musculoskeletal model in the AnyBody Modeling System. Results: No statistically significant differences were found for the duration of the turn in both pirouettes. The range of motion in all joints of supporting leg in sagittal plane and in hip joint in frontal plane for non-supporting leg were significantly higher in classic pirouette. The ankle joint was the most loaded joint in both pirouettes and its maximal value was significantly higher in classic pirouette. The force generated by ankle plantar flexors muscles was significantly greater in the jazz pirouette in turn phase. For the nonsupport limb, external hip rotators generated significantly greater force when performing the classic pirouette. Conclusions: It seems that early stage dancers may start their lessons with jazz pirouettes, where necessary joint mobility is lesser. They also are supposed to increase muscle strength and body awareness with such proceedings. A better awareness of the mechanical loads on the musculoskeletal system which a dancer performing pirouettes faces should have an impact on the way dance classes are conducted and choreographic elements are sequenced.
\end{abstract}

Key words: kinetics, muscle force, dance, joint loading, pirouettes

\section{Introduction}

Modern-day dancers may practice any of a whole range of various techniques and styles, such as hiphop, musical theater, jazz, folk, modern and classical ballet. Although footwear may be chosen to suit performance choreography, most dance techniques, such as modern ballet, are performed barefoot. As a consequence, the absence of shock absorption and the demands placed on dancers' lower extremities leave them at risk of musculoskeletal injuries. Previous studies have reported injury incidence rates of $67 \%$ to $95 \%$ among professional ballet dancers and $17 \%$ to $24 \%$ among modern dancers [5], [7]. The extreme positions adopted when dancing on pointe (on the tips of the toes) can lead to both acute injuries and repetitive strain injuries of the foot and ankle. Therefore, these parts of the body are particularly vulnerable to injury and indeed account for $34 \%$ to $62 \%$ of all injuries reported [23].

One of the most common movements in all forms of dance and also in sports acrobatics is the pirouette. In a pirouette, the dancer balances the body on one lower limb (the support leg) and performs single or multiple turns of the body with the other lower limb (the non-support leg), rotating around the pivotal axis provided by the support foot. Pirouettes can be performed in two different ways with regard to the rotational direction of the non-support leg: en dehors (outwards) and en dedans (inwards) [10], [21]. Traditional training preparing for pirouettes comes from the fourth (open) or fifth (closed) position. Dancers often start to practice turns around the age of ten and improve the skill through continual imitation of the

\footnotetext{
* Corresponding author: Michalina Błażkiewicz, Józef Piłsudski University of Physical Education, ul. Marymoncka 34, 00-968, Warsaw, Poland. Phone: 503121 114, e-mail: michalinablazkiewicz@gmail.com

Received: June 9th, 2020

Accepted for publication: October 5th, 2020
} 
movement pattern by guesswork, and practicing repeatedly via trial and error [13]. This is what happens if teachers use the old method of learning pirouette (observed in sports acrobatics based on the author's experience). However, this ineffective learning process often prolongs the practice time, and may thus lead to fatigue and injury. Although several biomechanical studies have been conducted on pirouettes en dehors, the focus of those studies is mainly on the preparatory posture [18], axis of rotation [3], and toppling [14]. To our knowledge, no study has investigated the muscle force distribution and joint load in dancers' legs during the performance of pirouettes. As it is impossible to measure muscle forces and joint reaction forces directly during a given movement, the AnyBody modeling system was used to estimate these parameters [1]. The specific objective of this study was to analyze the muscle force distribution during two types of pirouettes: classic and jazz on demi-plié and check which muscle of lower limb in which pirouette generates the highest force. Additionally, an at- tempt was made to assess which joint in which pirouette is the most loaded.

\section{Materials and methods}

\subsection{Participants and procedures}

The study group comprised of sixteen female contemporary dancers, with sports acrobatics as the basic preparation - mean age of $22.13 \pm 2.73$ years, mean height of $1.68 \pm 0.62 \mathrm{~m}$, and mean weight of 57.56 $\pm 6.76 \mathrm{~kg}$. Their average dance instruction experience was $12.19 \pm 3.04$ years. The participants reported having no existing lower limb injuries or balance disorders, and had not undergone any major lower limb surgery. The study was conducted according to the ethical guidelines and principles of the Declaration of Helsinki.

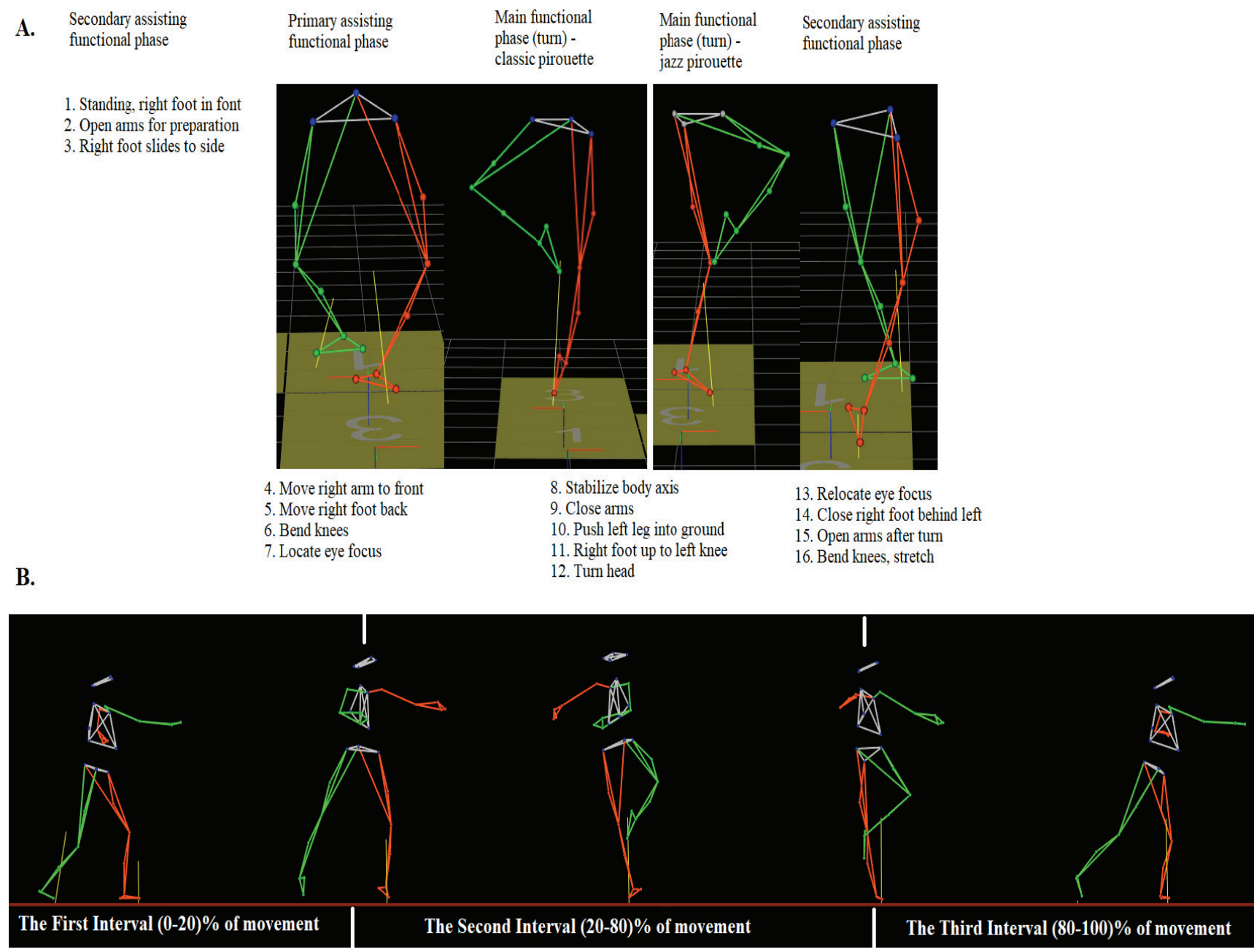

Fig. 1. Pirouette en dehors. A - Functional phases are given above the stick figure, basic action concepts are listed with numbers below the stick figures [21], B - Phases which were taken for kinematics and kinetics analysis 
Data on the kinematics and kinetics of the two types of single-turn pirouette en dehors (Fig. 1), i.e., classic and jazz on demi-plié, were collected using a 9-camera system (Vicon, Oxford Metrics, Ltd., UK) operating at $100 \mathrm{~Hz}$, with a standard lower body Plugin-Gait (15 markers) set. Two force plates (Kistler Holding AG, Switzerland) were used to determine ground reaction forces (GRF). The force plates were synchronized to the motion capture system. All participants were barefoot and performed one turn with the left leg support, rotating in the clockwise direction. The phases of the analyzed pirouettes are describe below [4].

\subsection{Phases of pirouettes}

The pirouette en dehors (classic and jazz) can be separated into four functional phases (Fig. 1A). It begins with a preparation (secondary assisting functional phase) during which the body is aligned facing front, the arms open to the sides and the non-supporting leg slides sideward. In the primary assisting functional phase, the non-supporting leg slides back to the fourth position in which it is placed behind the supporting leg, the corresponding arm is moved to the front and the knees are bent. From here, the turn is initiated by pushing the ground with the non-supporting leg and moving the foot up to the knee of the supporting leg (it stays there throughout the turn), pushing up onto point or demi-point (the ball of the foot) with the supporting leg, and closing both arms in front. During the final assisting phase, the turn is halted, the non-supporting leg is placed on the ground, the arms open and a terminal pose is adopted [4], [21]

The main difference in the performance of the two pirouettes is the knee flexion and ankle plantar flexion of the support leg. In the classic pirouette, the knee joint is fully extended and the ankle joint should have maximum plantar flexion for the dancer, whereas for the jazz pirouette, the knee joint should be bent and the plantar flexion is much smaller. Additionally, hip external rotation of non-supporting leg should be greater in the classic pirouette compared to the jazz one. Although the entire pirouettes were recorded, mainly the turn phase was taken for analysis. This was done due to the fact that the dancers did not have the duration of the primary assisting phase imposed. The movement analyzed in this study started with the bending of the knees and finished when the foot of non-supporting leg first touched the ground. Since the dancers had different rotation times, analyzed movement was normalized to $100 \%$ (Fig. 1B).

\subsection{Data analysis}

In base of kinematics data from Vicon system, the horizontal pelvis line was calculated as the maximal difference in elevation of the anterior superior iliac spines during a pirouette, using following formula: $\max ($ RASI_z - LASI_z), where: RASI_z, LASI_z - vertical coordinate of right and left anterior pelvis markers. Moreover, in order to see the differences between the pirouettes the range of motion for lower limb joint angles and pelvis was analyzed.

The kinematic and kinetic data of one trial for each pirouette were imported into the AnyBody 7.0 (AnyBody Technology, Denmark) software to calculate the lower limb muscle forces and joint reaction forces. The kinematic and kinetic data were filtered using a Butterworth low pass filter with 10 and $15 \mathrm{~Hz}$ cut-off frequencies, respectively. The standard musculoskeletal model was used in this study (AMMR 1.6.6, MoCapModel-LowerBody). The model of each leg has seven degrees of freedom: three hip joints, one knee joint, one ankle joint, one subtalar joint and one patellar movement. Mass, moments of inertia and muscle geometry of all segments were modelled according to the morphological dataset for the lower extremities provided by Klein Horsman et al. [11]. Moreover, each lower limb model comprised of 55 muscles divided in 159 fascicles. Muscles were modelled using the Hill-type model [9]. The generic model was scaled to match each participant's anthropometry in accordance with Length-Mass-Fat scaling law [1]. Muscle tendon unit properties (e.g., maximum isometric forces) stayed the same across participants and, therefore, have not been scaled to the participant's anthropometrics. Inverse dynamics was performed in order to calculate external joint moments in each joint. For estimating muscle forces, static optimisation was solved by minimising the polynomial muscle recruitment criterion, defined as: $G=\sum_{i=1}^{n M}\left(\frac{f_{i}^{M}}{N_{i}}\right)^{3}$, where: $n M$ is the number of muscles, $f_{i}^{M}$ is the respective muscle force, $N_{i}$ is equal to the isometric muscle strength in the simple muscle model [17]. The following muscles were analyzed. For support leg these were: soleus, gastrocnemius medialis and lateralis, tibialis posterior, flexor digitorum longus, flexor hallucis longus, peroneus brevis and longus, rectus femoris, semitendinosus, semimembranosus, biceps femoris (caput longus and brevis) and the iliacus. For the non-support limb, mainly external hip rotators (piriformis, gracilis, gemellus (inferior and superior), quad- 
rates femoris, gluteus maximus, gluteus medius and obturator) were considered.

The muscle forces, joint reaction forces and ground reaction forces were normalized to body weight (x BW). For joint reaction forces, the resultant curve were calculated using the following formula: $\sqrt{A / P^{2}+M / L^{2}+P / D^{2}}$ where $A / P$ stands for the value in the anterior-posterior axis, $M / L$ in the mediolateral axis, and P/D in the proximal-distal axis. In order to compare the curves of kinetics parameters for the jazz and classic pirouettes, parameterization method was used. In this work, the parameterization consisted of selecting representative points on a given curve, which were local minima and maxima. The smallest and largest characteristic values of the kinetics curves within a three intervals were selected (Figs. 3 and 4). The first interval: $(0-20 \%)$ of the movement (double leg support), where the dancer from bent knees started the turn; the second interval: middle phase of the pirouette $(20-80 \%)$ of the movement (single leg support), where the dancer turns; the last interval: final phase $(80-100 \%)$, where there was a deceleration and preparation to put the foot on the ground. The statistical analysis was conducted with Statistica 12 (StatSoft, Inc., USA). The significance level was set at 0.05 . The requirements for normality in the data using the ShapiroWilk test were satisfied only by certain parameters. For this reason and also because of the small number of participating dancers, the non-parametric Mann-Whitney $U$-test was used to show statistically significant differences between the analyzed pirouettes.

\section{Results}

\subsection{Kinematic parameters}

No statistically significant differences were found for the duration of the turn in the jazz and classic pirouette, although the classic pirouette was slightly longer $(1.07 \pm 0.29$ vs. $0.85 \pm 0.15 \mathrm{~s})$. Analyzing the horizontal pelvis line, it turned out that the anterior superior iliac spine of non-supporting leg raised significantly higher $(p=0.0022)$ in the classic pirouette in comparison with the jazz one $(8.71 \pm 1.11$ vs. 6.57 $\pm 1.21 \mathrm{~cm})$.

\section{Supporting leg}

Statistically significant differences between the two pirouettes, related to the range of motion of all joints, were found only for flexion and extension movement. However, for the knee joint, such differences were observed in the other two planes as well. Note that the initial and final positions in both pirouettes were similar, therefore the dancers' behavior during the turn had a direct impact on the differences shown (Fig. 2A).

For the hip joint, in the classic pirouette, the range of motion was $\left(45.8 \pm 6.8^{\circ}\right)$ and was significantly higher $(p=0.0001)$ than that obtained for the jazz pirouette $\left(28.4 \pm 9.4^{\circ}\right)$. In both pirouettes, the hip joint was in the flexed position. At the same time, the average minimum flexion value for the classic pirouette was $2.4^{\circ}$, while for the jazz pirouette it was $22.8^{\circ}$, and these values were achieved in the middle of turn phase. For the knee joint, a significantly higher range of motion $(p=0.0001)$ was observed also for the classic pirouette $\left(52.3 \pm 11.2^{\circ}\right.$ vs. $\left.26.8 \pm 9.1^{\circ}\right)$ in the sagittal plane. Such large values for the range of knee flexion were caused by the average minimum bend value, which was $2^{\circ}$ in the classic pirouette, but $33^{\circ}$ for the jazz pirouette. For the other planes, the comparative data (classic vs. jazz) were as follows: $\left(32.1 \pm 7.1^{\circ}\right.$ vs. $\left.20.4 \pm 8.4^{\circ}\right)$ for the frontal plane, and $\left(35.5 \pm 9.1^{\circ}\right.$ vs. $28.2 \pm 15.2^{\circ}$ ) for the transverse plane. A similar situation was observed for the ankle joint, which remains in the plantar flexion position during the entire pirouettes. For the classic pirouette, the range of plantar flexion reaches $\left(54 \pm 11^{\circ}\right)$, which was $31^{\circ}$ more than for the jazz pirouette.

\section{Non-supporting leg and pelvis}

As for the support leg, range of motion related to the joints of non-support limb was significantly higher for the classic pirouette for knee joint in all planes and for hip joint only in frontal plane (Fig. 2B). For the knee joint, the highest range of motion was in the sagittal plane $\left(140.2 \pm 8.5^{\circ}\right.$ vs. $\left.106.5 \pm 16.1^{\circ}\right)$. For hip joint, the comparative data (classic vs. jazz) were as follows: $\left(45.2 \pm 15.5^{\circ}\right.$ vs. $\left.24.6 \pm 4.9^{\circ}\right)$ only for the frontal plane. No statistically significant differences were found for the pelvis (Fig. 2C).

\subsection{Ground reaction forces and joint reaction forces in the support leg}

For non-supporting leg (right), during the first phase $(0-20 \%)$ of motion, significantly higher values of the vertical and medio-lateral component of GRF were recorded for the classic pirouette (Fig. 3A), while for 


\section{A. Supporting leg}
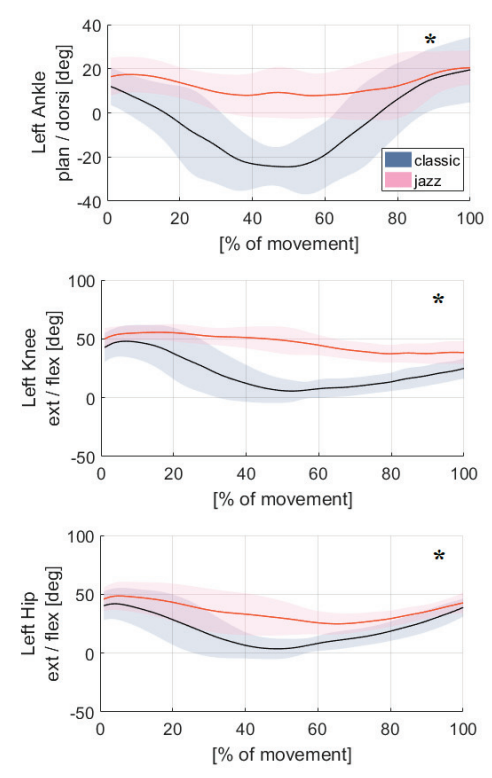

B. Non supporting leg
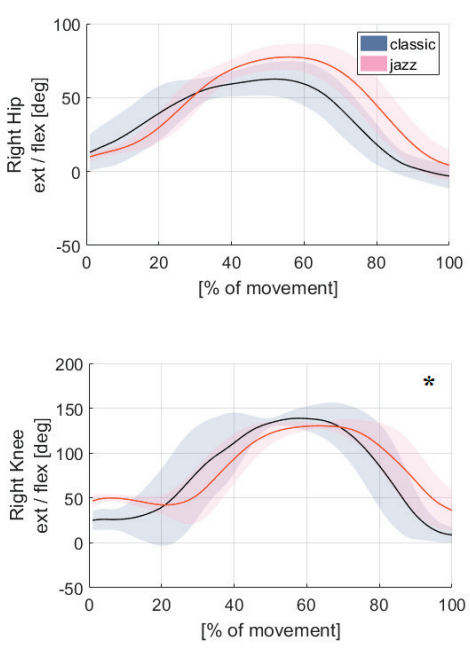

C. Pelvis kinematics
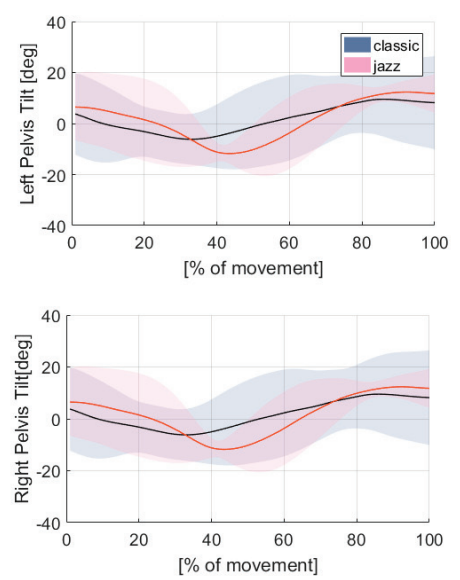
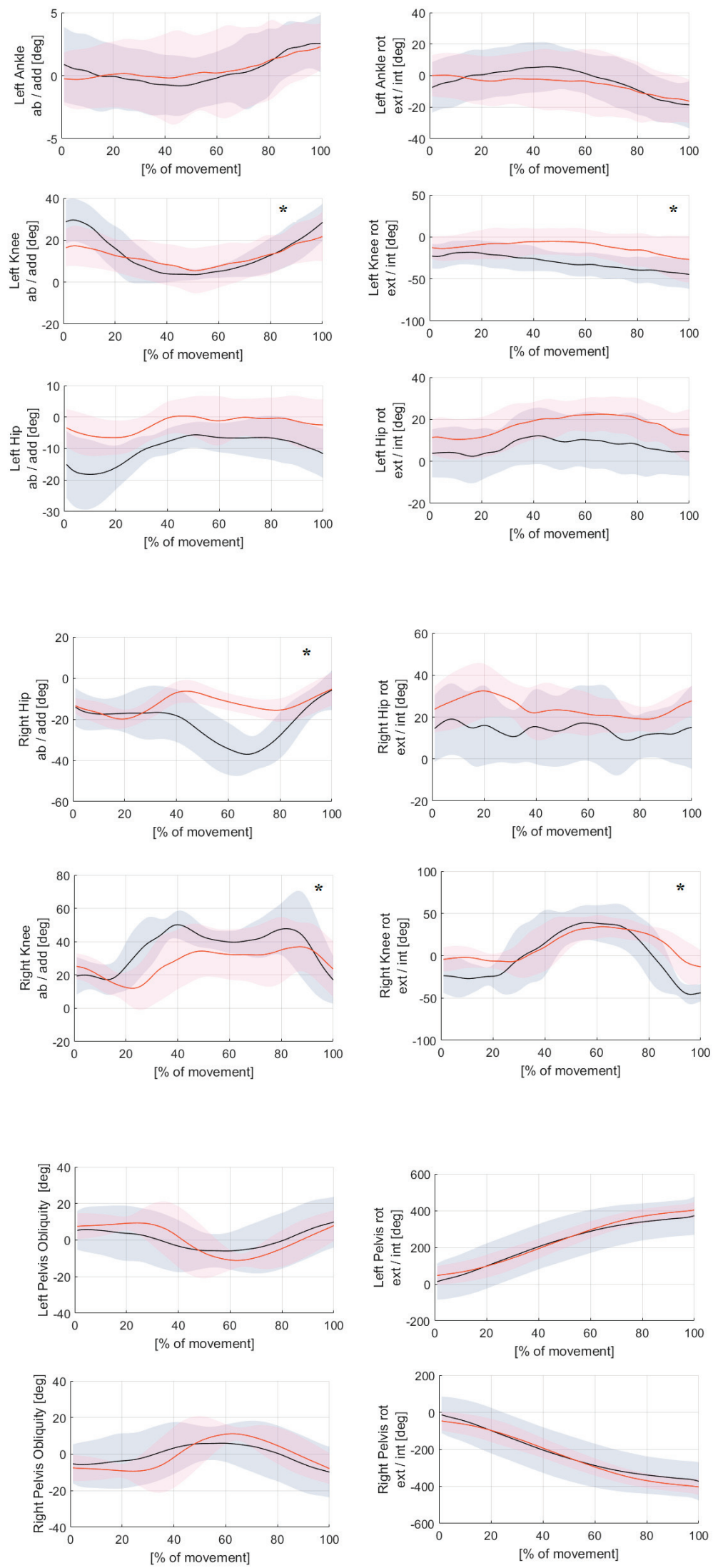

Fig. 2. Kinematic parameters in lower limb joints during classic and jazz pirouettes for:

$\mathrm{A}$ - support leg, B - non-support leg, $\mathrm{C}$ - pelvis, where: ext/flex - extension/flexion, $\mathrm{ab} / \mathrm{add}$ - abduction/adduction, ext/int - external and internal rotation; * - significant differences for range of motion, $p<0.05$ 
support leg (left), significantly higher values were observed in the final phase (80-100\%) for jazz pirouette for the same components of GRF as for the nonsupporting leg. In Figure 3B, showing the distribution of reaction forces in the joints of the support limb, clear differences were visible in the turn phase (20$80 \%$ ), where significantly higher values occured for the jazz pirouette.
In the final phase (80-100\%) not significantly higher values were achieved for the classic pirouette. The maximum resultant values of reaction forces in the joints (classic vs. jazz pirouette) were then achieved in the following order: ankle $(11.07 \pm 1.90) \mathrm{BW}$ vs. $(9.32 \pm 2.73) \mathrm{BW}$, knee $(7.96 \pm 1.53) \mathrm{BW}$ vs. $(6.71$ $\pm 1.15) \mathrm{BW}$, and hip $(6.13 \pm 1.61) \mathrm{BW}$ vs. $(5.88 \pm$ 1.07) BW. The resultant load in a given joint consists
A.
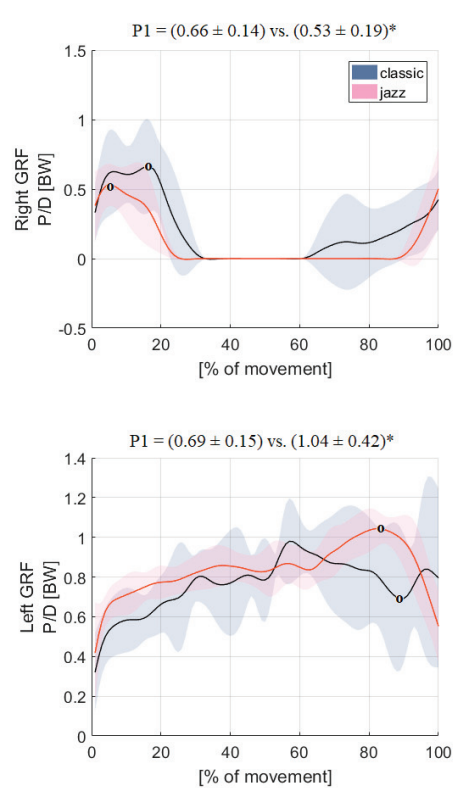
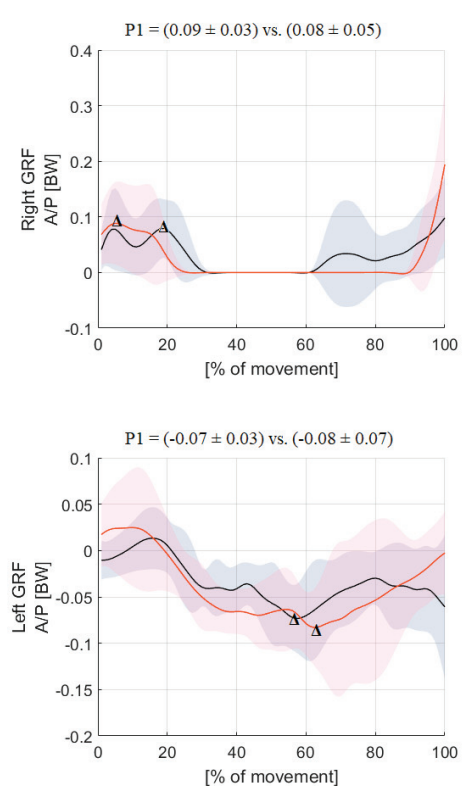
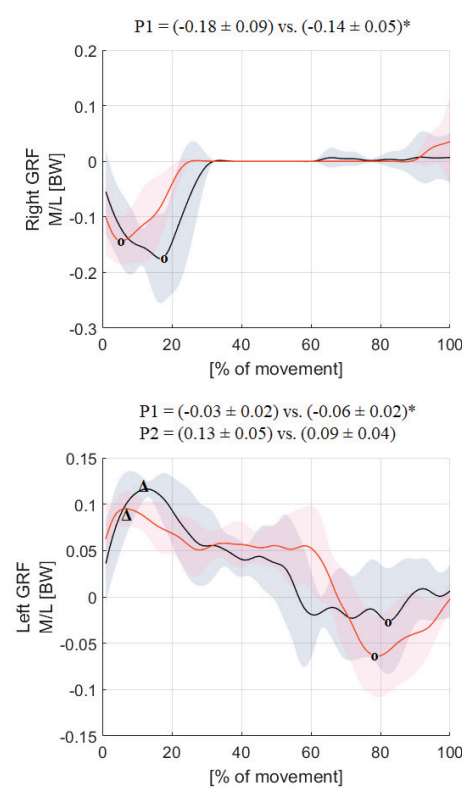

B.

$\mathrm{Pl}=(0.39 \pm 0.14)$ vs. $(0.13 \pm 0.05)^{*}$

$\mathrm{P} 2=(1.46 \pm 0.34)$ vs. $(1.45 \pm 0.31)$

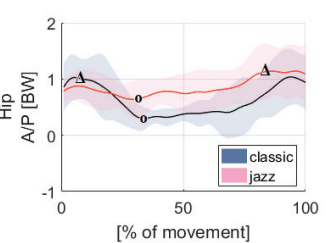

$\mathrm{P} 1=(1.46 \pm 1.05)$ vs. $(0.25 \pm 0.1)^{*}$ $\mathrm{P} 2=(4.27 \pm 1.35)$ vs. $(5.04 \pm 2.47)$

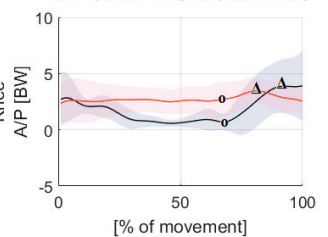

$\mathrm{P} 1=(0.41 \pm 0.19)$ vs $(0.07 \pm 0.01)^{*}$ $\mathrm{P} 2=(1.60+0.52)$ vs. $(1.93+0.87)$

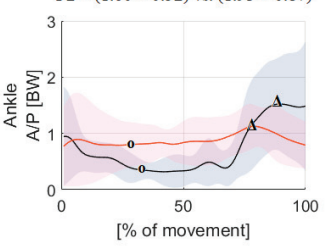

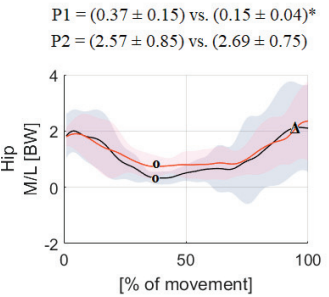

$\mathrm{Pl}=(0.44 \pm 0.17)$ vs. $(0.19 \pm 0.06)^{*}$ $\mathrm{P} 2=(1.17 \pm 0.19)$ vs. $(1.40 \pm 0.45)$
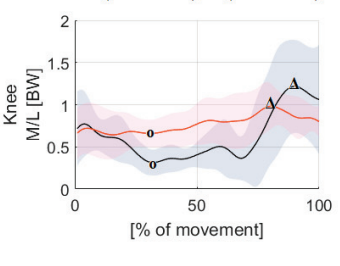
$\mathrm{P} 1=(0.58 \pm 0.36)$ vs. $(0.41 \pm 0.12)$
$\mathrm{P} 2=(2.23 \pm 0.63)$ vs. $(2.81 \pm 0.65)$

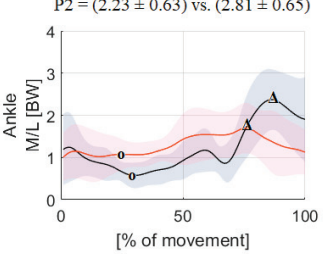

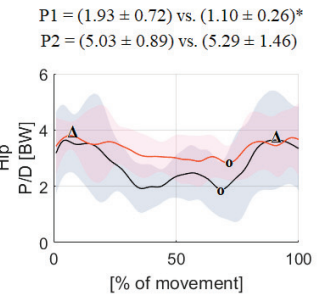

$\mathrm{P} 1=(2.02 \pm 0.5)$ vs. $(1.11 \pm 0.42)^{*}$ $\mathrm{P} 2=(4.96 \pm 0.49)$ vs. $(5.85 \pm 1.47)$

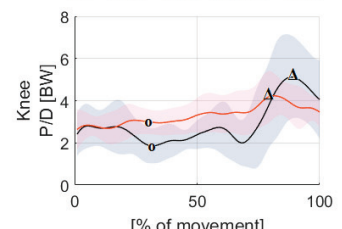

$\mathrm{P} 1=(2.08 \pm 1.26)$ vs. $(1.75 \pm 0.37)$

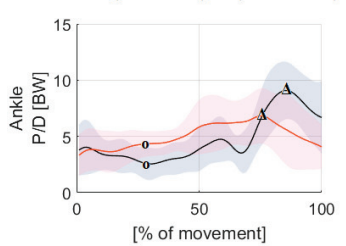

$\mathrm{P} 1=(2.01 \pm 0.72)$ vs. $(1.12 \pm 0.25)^{*}$ $\mathrm{P} 2=(5.88 \pm 1.07)$ vs. $(6.13 \pm 1.61)$

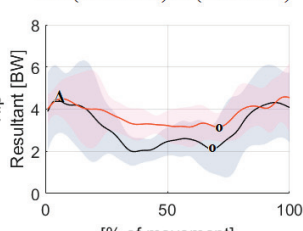

[\% of movement]

$\mathrm{P} 1=(2.60 \pm 1.03)$ vs. $(1.16 \pm 0.42)^{*}$ $\mathrm{P} 2=(6.71 \pm 1.15)$ vs. $(7.96 \pm 1.53)$

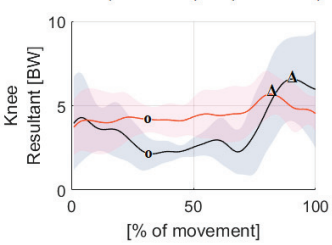

$\mathrm{P} 1=(2.21 \pm 1.31)$ vs. $(1.81+0.38)$ $\mathrm{P} 2=(9.32 \pm 2.73)$ vs. $(11.07 \pm 1.90)$

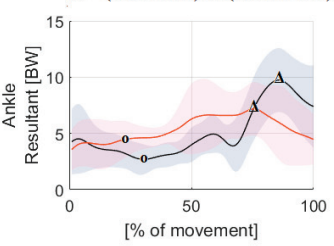

Fig. 3. Kinetic parameters during the classic and jazz pirouette (classic vs. jazz) and maximal (minimal) values of:

A - mean ground reaction forces for non-support leg (right) and for support leg (left), B - lower limb mean joint reaction forces, where: $\mathrm{A} / \mathrm{P}$ - anterior-posterior, $\mathrm{M} / \mathrm{L}$ - medio-lateral, $\mathrm{P} / \mathrm{D}$ - proximal-distal components; $\Delta$ - values for which there are no statistically significant differences, $\mathrm{o}-$ values taken for parameterization; $*$ - statistically significant differences, $p<0.05$ 
of loads generated along each axis. Therefore, it is worth noting that the maximum loads were visible along the proximal-distal axis. For this direction, the highest values were achieved in the ankle joint $(10.50 \pm 1.74)$ BW vs. $(8.89 \pm 2.65) \mathrm{BW}$, for classical and jazz pirouette, respectively. In contrast, the loads for both the knee and hip joints in both pirouettes amounted to $5 \mathrm{BW}$.

Another direction affecting the resultant values of reaction forces in the joints is the anterior-posterior axis. Here, the maximum values were reached in the knee joint $(4.27 \pm 1.35) \mathrm{BW}$ vs. $(5.04 \pm 2.47) \mathrm{BW}$, then in the ankle and hip, reaching on average $1.61 \mathrm{BW}$. The smallest values were generated along the medio-lateral axis. Similar loads for both pirouettes were generated in the ankle and hip joints and they amounted to 2.57 BW on average.

Minimum load values were recorded in the middle phase of the pirouettes, when the dancer keeps her full balance. Here, the greatest values occured for the jazz pirouette. Statistically significant differences for the resultant reaction forces in the joints occured between the jazz and classical pirouette $-(2.60 \pm 1.03) \mathrm{BW}$ vs. $(1.16$ $\pm 0.42) \mathrm{BW}$ for the knee and $(2.0 \pm 0.72) \mathrm{BW}$ vs. $(1.12$ $\pm 0.25) \mathrm{BW}$ for the hip. These values were significantly affected by the loads in the proximal-distal direction.

\subsection{Muscle force distribution}

\section{Support leg}

For the supporting limb, the ankle plantar flexor muscles, the knee flexors and two hip flexors were taken into account. It has been shown that during the turn phase $(20-80 \%)$, the force generated by ankle plantar flexors muscles (soleus, tibialis posterior, flexor digitorum longus, flexor hallucis longus) was significantly greater in the jazz pirouette. It is worth mentioning that only in the final phase $(80-100 \%)$ for the classic pirouette a significantly greater force was generated by the triceps surae muscle. Considering the knee flexors, just muscle biceps femoris generated significantly greater force in the turn phase for the jazz pirouette. Rectus femoris and iliopsoas as hip flexors, generated significantly greater force during turn phase for jazz pirouette. Moreover, the highest average force level was observed for the tibialis posterior muscle $(6.28 \pm 2.44) \mathrm{BW}$ vs. $(4.80 \pm 2.73) \mathrm{BW}$ during jazz and classic pirouette, respectively.

\section{Non-support leg}

For the non-support limb, the analysis included mainly external hip rotators. It has been shown that these muscles generated significantly greater force when performing the classic pirouette. Only the obturator muscle was significantly stronger in the jazz pirouette, for the entire duration of the movement. Additionally, in the jazz pirouette, gluteus medius showed a much greater level of force in the initial phase of movement. It is worth noting that the highest average force level was observed for the obturator muscle $(2.52 \pm 0.57) \mathrm{BW}$ during jazz pirouette and for gluteus maximus (2.80 $\pm 0.99) \mathrm{BW}$ during classic pirouette.

\section{Discussion}

The objective of this study was to analyze the muscle force distribution during two types of pirouettes: classic and jazz on demi-plié and check which muscle of lower limb in which pirouette generates the highest force. Additionally, an attempt was made to assess which joint in which pirouette is the most loaded. Sugano and Laws [18] demonstrated that a dancer's initial posture, especially the relation to foot distance and weight distribution, is crucial for the ability to control the turn. They identified the fourth position as ideal for creating angular momentum, as the feet exert equal horizontal forces in opposite directions to produce a twisting effect. They also reported that in the preparation for successful turns, approximately $60 \%$ of the dancer's weight was over the front foot, necessitating a 'wider' fourth position. The dancers participating in this research started and finished both the classic and jazz pirouettes in the recommended fourth position. No statistically significant differences were found for the duration of the turn in the jazz and classic pirouette, although the classic pirouette was slightly longer $(1.07 \pm 0.29$ vs. $0.85 \pm 0.15 \mathrm{~s})$. Analyzing the horizontal pelvis line, it turned out that the anterior superior iliac spine of non-supporting leg raised significantly higher $(p=0.0022)$ in the classic pirouette compared to jazz one $(8.71 \pm 1.11 \mathrm{vs} .6 .57 \pm 1.21 \mathrm{~cm})$. Moreover, it was found that the largest ranges of motion for all lower limb joints occur in the classic pirouette in the sagittal plane. For the hip joint, on average, the range of motion was $17.4^{\circ}$ greater than that observed in the jazz pirouette; for the knee joint it was $25.5^{\circ}$ greater; and for the ankle joint $31^{\circ}$ greater. Analyzing the range of motion in the joints for the non-support limb, it was shown that the abduction movement in the hip joint was significantly greater during the classic pirouette. Moreover, in this pirouette, significantly greater movements were also recorded for the knee joint in all planes. Such 
A.

$\mathrm{P} 1=(0.43 \pm 0.05)$ vs. $(1.48 \pm 0.41)^{*}$ $\mathrm{P} 2=(1.91 \pm 0.22)$ vs. $(0.92 \pm 0.20)$

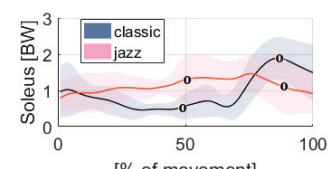

[\% of movement]

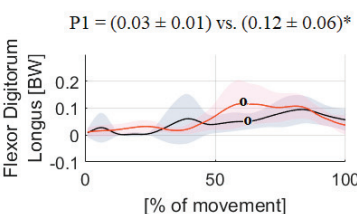

$\mathrm{P} 1=(0.02 \pm 0.01)$ vs. $(0.12 \pm 0.02)^{*}$

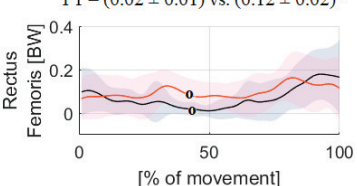

[\% of movement]

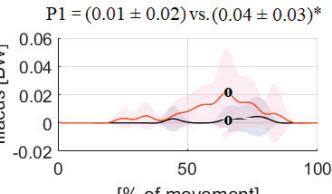

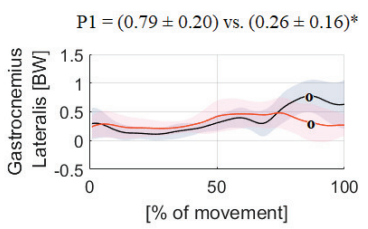

$\mathrm{Pl}=(0.35 \pm 0.05)$ vs. $(0.98 \pm 0.14)^{*}$
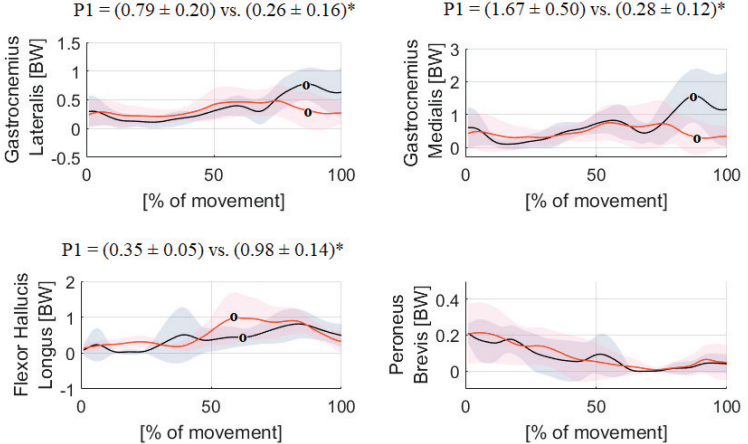
$\mathrm{P2}=(0.07 \pm 0.03)$ vs. $(0.33 \pm 0.07)^{*}$
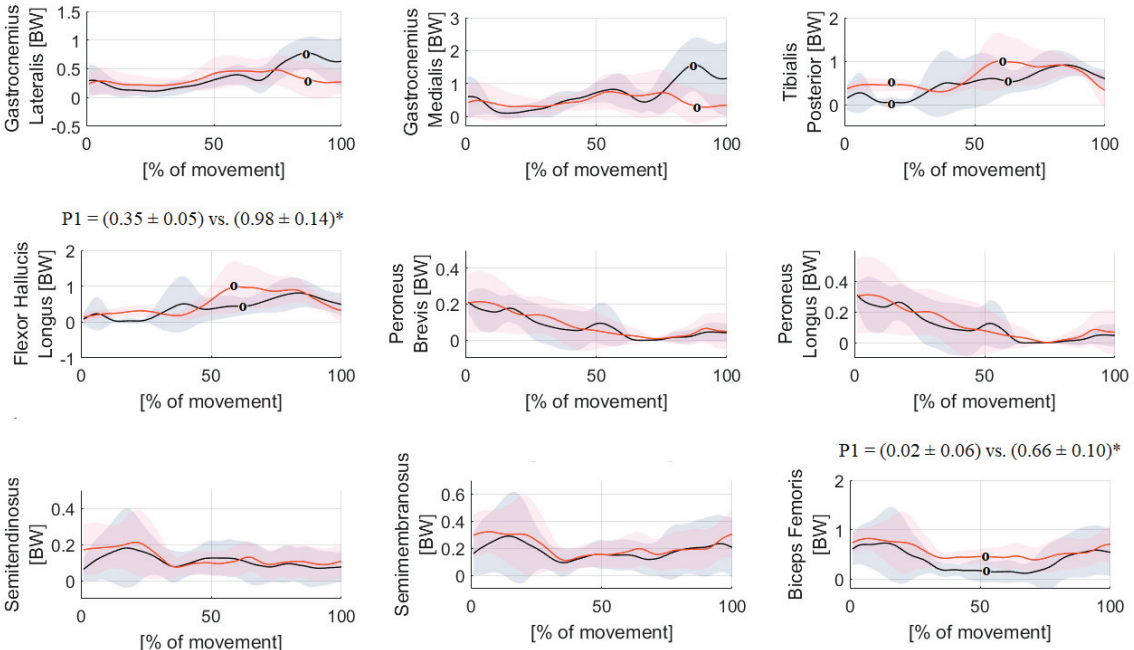

B.

$\mathrm{P} 1=(0.24 \pm 0.04)$ vs. $(0.03 \pm 0.02)^{*}$

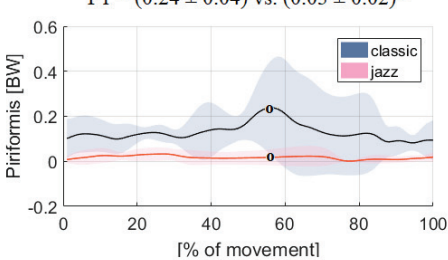

$\mathrm{P} 2=(0.11 \pm 0.02)$ vs. $(0.03 \pm 0.02)$

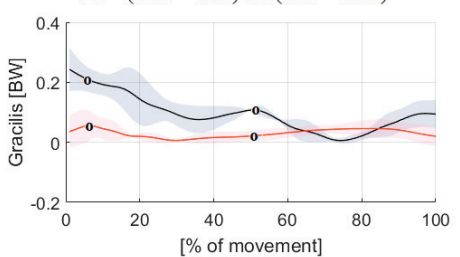

$\mathrm{P} 1=(0.28 \pm 0.08)$ vs. $(0.00 \pm 0.00)^{*}$ $\mathrm{P} 2=(0.45 \pm 0.14)$ vs. $(0.05 \pm 0.03)^{*}$
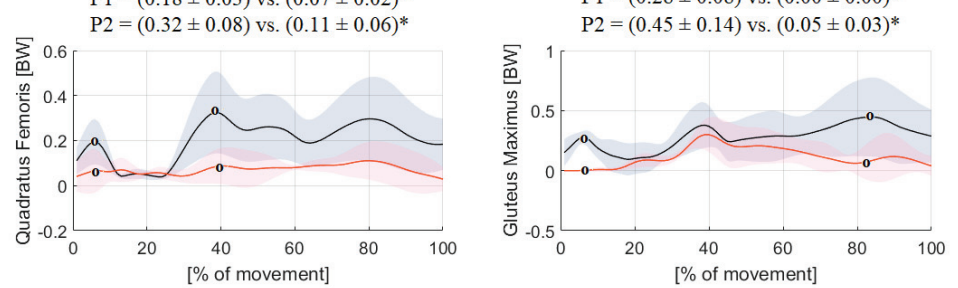

$\mathrm{P} 1=(0.09 \pm 0.02)$ vs. $(0.06 \pm 0.01) *$ $\mathrm{P} 2=(0.09 \pm 0.03)$ vs. $(0.03 \pm 0.01)$

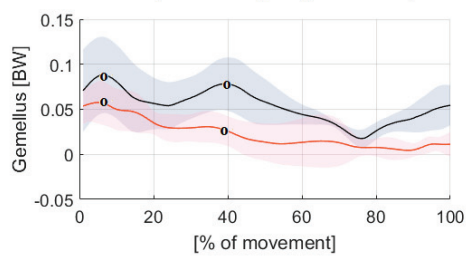

P1 $=(0.10 \pm 0.03)$ vs. $(0.25 \pm 0.05) *$ $\mathrm{P} 2=(0.15 \pm 0.05)$ vs. $(0.03 \pm 0.05)^{*}$ $\mathrm{P} 3=(0.17 \pm 0.07)$ vs. $(0.00 \pm 0.0)^{*}$
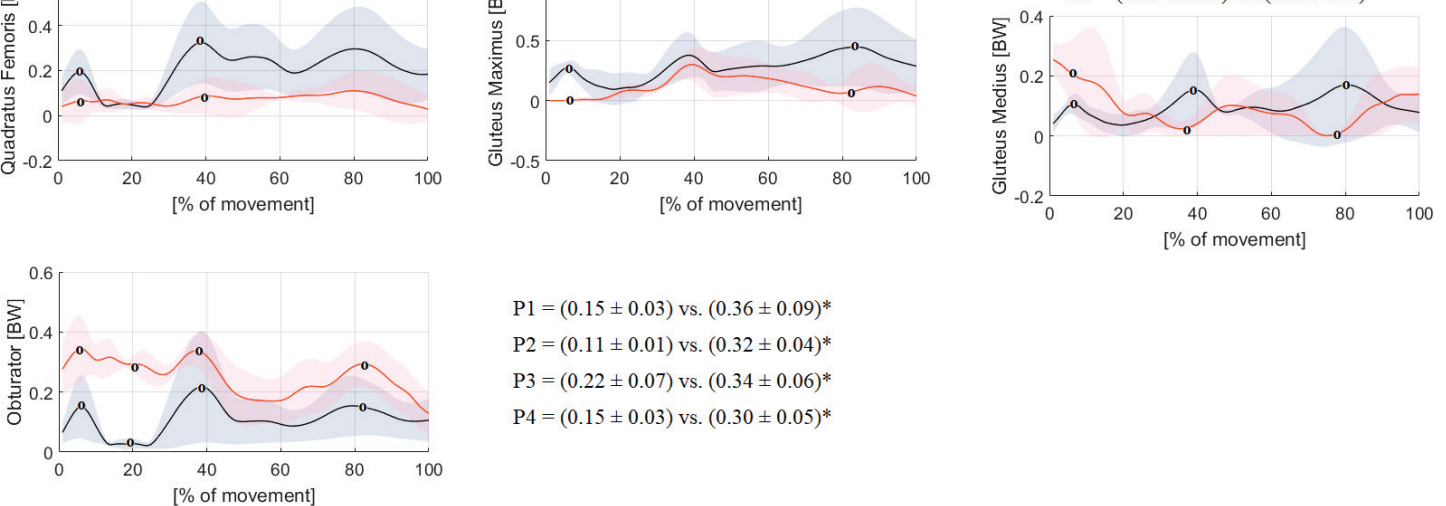

$\mathrm{P} 1=(0.15 \pm 0.03)$ vs. $(0.36 \pm 0.09)^{*}$ $\mathrm{P} 2=(0.11 \pm 0.01)$ vs. $(0.32 \pm 0.04)^{*}$ $\mathrm{P} 3=(0.22 \pm 0.07)$ vs. $(0.34 \pm 0.06)^{*}$ $\mathrm{P} 4=(0.15 \pm 0.03)$ vs. $(0.30 \pm 0.05)^{*}$

Fig. 4. Lower limb mean muscle forces during the classic and jazz pirouette (classic vs. jazz) for: A - support leg, $\mathrm{B}$ - non-support leg, where: $\mathrm{o}$ - values taken for parameterization; ${ }^{*}$ - statistically significant differences, $p<0.05$

differences may affect primarily the muscle work and loads generated in the joints mainly of support limb. Dance performance requires flexibility and strength. Lower extremity strength is not only essential for the performance of dynamic maneuvers such as leaps and jumps, but is also vital for the balance and postural control in various positions, such as arabesque or pirouette. Research has shown that professional ballet dancers appear to have reduced fitness levels with regard to muscle strength [2], [6] and aerobic capacity [20], [24] in comparison with athletes practicing other activities/sports. 
When analyzing the values of the ground reaction forces, it can be noticed that higher forces were generated for the classic pirouette for the support limb and for the non-support leg only during push off phase (0-20\%). However, these values were smaller than those generated during gait or some dance evolutions [8]. Going deeper, into the forces inside the joints, finding of this paper unfortunately indicate that the forces generated in the joints during the proper performance of jazz and classic pirouettes are much greater, often significantly exceeding the forces occurring during walking, for instance. The maximum values for the joint reaction force during gait are 5.2, 7.1 and 5.4 times the body weight for the ankle, knee and hip joint, respectively [16]. In the classic pirouette, the maximum resultant reaction forces in the joints are significantly higher (classic vs. jazz pirouette): ankle $(11.07 \pm 1.90) \mathrm{BW}$ vs. $(9.32 \pm 2.73) \mathrm{BW}$, knee $(7.96 \pm 1.53) \mathrm{BW}$ vs. $(6.71 \pm 1.15)$ BW and hip $(6.13 \pm 1.61)$ BW vs. $(5.88$ $\pm 1.07) \mathrm{BW}$. This finding shows that ankle joint is the most loaded joint during both types of pirouettes and the resultant reaction forces in the joints are significantly higher in classic pirouette. Therefore, these high values of joint reaction forces explain the causes of numerous injuries and frequent pain in dancers. Trauma in dancers results not only from the impact of the highest overloads occurring during a single performance or a single pirouette, but also from the accumulation of high impact over the duration of an entire professional career [8], [16]. The occurrence of such heavy loads should be counteracted by strong muscles able to stabilize the joints. For support leg, there are six key muscle groups that need to be engaged in order to successfully complete a pirouette. The first group includes plantar flexors (triceps surae, flexor hallucis and digitorum longus, tibialis posterior, peroneus longus and brevis) that play the crucial role here, because their action helps the dancer to rise up on relevé. The second muscle group include knee flexors (biceps femoris, semimembranosus and semitendinosus). The final group consists of the hip flexor muscles (the iliacus and rectus femoris). Bolstered flexibility and strength in all these areas will assist the dancer to stay upright and lifted during a pirouette. Plantar flexion of the foot is caused by the action of the calf muscles. These are powerful muscles, playing the key role in keeping balance. Finding of this paper shows that the force generated by ankle plantar flexors muscles (soleus, tibialis posterior, flexor digitorum longus, flexor hallucis longus) is significantly greater in the jazz pirouette. This is because the soleus is the most effective muscle for plantar flexion in a bent knee position. The flexor hallucis longus, flexor digi- torum longus and tibialis posterior are three deep muscles of the posterior compartment of the leg. The tibialis posterior is the most powerful of these deep muscles and has a major role in supporting the medial arch of the foot, which is very important when performing pirouettes. In both pirouettes, this muscle generates the greatest average force: $(6.28 \pm 2.44) \mathrm{BW}$ vs. $(4.80 \pm 2.73) \mathrm{BW}$ for the jazz and classic pirouettes, respectively. At this point, it is important to underline the fact that only in the final phase (80-100\%) for the classic pirouette a significantly greater force was generated by the triceps surae muscle. This is due to the fact that the greater range of motion in the knee joint present in the classic pirouette means that the triceps surae can affect force through the exchange of potential into kinetic energy [9]. Moreover, the gastrocnemius muscle originates on the femur, so bending the leg during jazz pirouette limits its effective tension. Turning with the knee joint bent to an average of $33^{\circ}$ resulted in the generation of significantly greater maximal muscle forces for the jazz pirouette, just for muscle biceps femoris. The other two muscles semitendinosus $((0.12$ $\pm 0.04) \mathrm{BW}$ vs. $(0.10 \pm 0.03) \mathrm{BW})$ and semimembranosus $((0.20 \pm 0.06) \mathrm{BW}$ vs. $(0.17 \pm 0.05) \mathrm{BW})$ generated similar mean force values in both pirouettes (jazz vs. classic). The only knee extensor considered in this study was the rectus femoris muscle. As in jazz pirouette, this muscle works in eccentric conditions, its maximal strength in the turn phase increases by $66.6 \%$ compared to classic pirouette. Worth emphasizing is the fact that the rectus femoris muscle is also hip flexor, but its function is weak when the knee is extended, because it is already shortened and thus suffers from active insufficiency. Therefore, the hip flexion action recruits more iliacus muscle. Iliacus muscle, as a hip flexor, generated significantly greater force during turn phase for jazz pirouette. For the nonsupport limb, the analysis included mainly external hip rotators The piriformis muscle is part of the lateral rotators of the hip, along with the quadratus femoris, gemellus inferior and superior, obturator externus and internus and gracillis. These muscles mainly abduct the femur with hip flexion, therefore, it has been shown that these muscles generate significantly greater force when performing the classic pirouette. The same tendency was noted for gluteus maximus and medius. Only the obturator muscle was significantly stronger in the jazz pirouette, for the entire duration of the movement. Its functions are to help abduct femur with hip flexion and to steady the femoral head in the acetabulum. It is worth noting that the highest average force level was observed for the obturator muscle $(2.52 \pm 0.57) \mathrm{BW}$ during jazz pirouette and for gluteus 
maximus $(2.80 \pm 0.99) \mathrm{BW}$ during classic pirouette. In both types of pirouettes, the greatest muscle strength and loads are generated within the ankle joint. The plantar flexors muscles of support limb, tibialis posterior muscle in particular, generate the most strength. The strongest muscles of the non-supporting limb are in the following order: obturator, gluteus maximus, quadrus femoris and piriformis. The weakest muscles in pirouette are the rectus femoris and iliacus. At this point, it's worth highlighting that the ankle joint is one of the most commonly injured body regions during dancing. Various studies place the incidence of ankle injuries between $4.7 \%$ and $54 \%$ of all injuries suffered by dancers [22]. The most common traumatic injury in dancers are ankle sprains, anterior impingement, posterior ankle pain, FHL tendonopathy, posterior tibial tendonopathy and Achilles tendinosis [15]. It has also been shown that weak and long hamstrings [12] and low or no endurance of postural muscles [19] are the cause behind the higher incidence of lower back injuries in dancers than in other types of athletes.

\section{Conclusions}

To sum up, for most of the kinematic parameters (ranges of motions for both limbs) significantly higher values were noted for the classic pirouette, which suggests that the dancers must be properly prepared for this type of pirouette in terms of flexibility. Additionally, dancers should have strong external hip rotators of non supporting leg. Therefore, it seems that the jazz pirouette is technically simpler, although the results of this paper show that in jazz pirouette the muscles generate significantly more force. In conclusion, it seems that early stage dancers may start their lessons with jazz pirouettes, where necessary joint mobility is lesser. They also will increase muscle strength and body awareness, with such proceedings. Therefore, a better awareness of the mechanical loads on the musculoskeletal system which a dancer performing pirouettes faces - such as provided by the findings discussed herein - should have an impact on the way dance classes are conducted and choreographic elements are sequenced.

The material of this research consisted of contemporary dancers who performed classical elements. This affected the quality of the classic pirouette, because dancers already had a "mannerist" since they have been doing elements of a different style for so many years. An additional limitation was that the dancers did not have an imposed pirouette rate, which means that the preparatory phases differed in length, therefore, only the turn phase was taken into account for the analysis.

\section{Acknowledgments}

This research was funded by the MNiSW in the year 2020-2022 under Research Group no 3 at Józef Pilsudski University of Physical Education in Warsaw "Motor system diagnostics in selected dysfunctions as a basis for planning the rehabilitation process" and statutory funds of the Medical University of Warsaw.

\section{References}

[1] Andersen M.S., Damsgaard M., MacWilliams B., RASMUSSEN J., A computationally efficient optimisation-based method for parameter identification of kinematically determinate and over-determinate biomechanical systems, Comput. Methods Biomech. Biomed. Engin., 2010, 13 (2), 171-83, https://www.ncbi.nlm.nih.gov/pubmed/19693717

[2] Bennell K., Khan K.M., Matthews B., De Gruyter M., COOK E., HOLZER K. et al., Hip and ankle range of motion and hip muscle strength in young female ballet dancers and controls, Br. J. Sports Med., 1999, 33 (5), 340-346. https://www.ncbi. nlm.nih.gov/pubmed/10522638, https://bjsm.bmj.com/content/ bjsports/33/5/340.full.pdf

[3] BIRINGen E.K., Analysis of pirouette execution for improved performance, Med. Probl. Perform. Art., 2010, 25 (3), 136-137, https://www.ncbi.nlm.nih.gov/pubmed/21265219

[4] Bläsing B., Schack T., Mental Representation of Spatial Movement Parameters in Dance, Spatial Cognition and Computation - SPAT COGN COMPUT, 2012, 12, 111-132.

[5] BRONNER S., OJOFEITIMI S., RoSE D., Injuries in a modern dance company: effect of comprehensive management on injury incidence and time loss, Am. J. Sports Med., 2003, 31 (3), 365-373, https://www.ncbi.nlm.nih.gov/pubmed/12750128

[6] Cale-Benzoor M., Albert M.S., Grodin A., Woodruff L.D., Isokinetic trunk muscle performance characteristics of classical ballet dancers, J. Orthop. Sports Phys. Ther., 1992, 15 (2), 99-106, https://www.ncbi.nlm.nih.gov/pubmed/18796792

[7] GARRICK J.G., ReQUA R.K., Ballet injuries. An analysis of epidemiology and financial outcome, Am. J. Sports Med., 1993, 21 (4), 586-590, https://www.ncbi.nlm.nih.gov/pubmed/8368421

[8] GORWA J., MichNIK R.A., NOWAKOWSKA-LIPIEC K., JURKOJC J., JOCHYMCZYK-WOZNIAK K., Is it possible to reduce loads of the locomotor system during the landing phase of dance figures? Biomechanical analysis of the landing phase in Grand Jete, Entrelace and Ballonne, Acta Bioeng. Biomech., 2019, 21 (4), 111-121, https://www.ncbi.nlm.nih.gov/pubmed/32022809

[9] Heinen F., Lund M.E., Rasmussen J., DE ZeE M., Muscletendon unit scaling methods of Hill-type musculoskeletal models: An overview, Proc. Inst. Mech. Eng. H., 2016, 230 (10), 976984, https://www.ncbi.nlm.nih.gov/pubmed/27459500

[10] Kim J., Wilson M.A., Singhal K., Gamblin S., Suh C.Y., KwON Y.H., Generation of vertical angular momentum in single, double, and triple-turn pirouette en dehors in ballet, Sports Biomech., 2014, 13 (3), 215-229, https://www.ncbi.nlm.nih.gov/ pubmed $/ 25325768$

[11] Klein Horsman M.D., KoOpman H.F., VAn der Helm F.C., Prose L.P., VeEger H.E., Morphological muscle and joint 
parameters for musculoskeletal modelling of the lower extremity, Clin. Biomech. (Bristol, Avon), 2007, 22 (2), 239-247, https:// www.ncbi.nlm.nih.gov/pubmed/17134801

[12] Kline J.B., Krauss J.R., Maher S.F., Qu X., Core strength training using a combination of home exercises and a dynamic sling system for the management of low back pain in pre-professional ballet dancers: a case series, J. Dance Med. Sci., 2013, 17 (1), 24-33, https://www.ncbi.nlm.nih.gov/pubmed/23498354

[13] LiN C.-W., Su F.-C., LIN C.-F., Difference of COM-COP Inclination Angle while Performing Ballet Turn (pirouette en dehors) in Novice and Experienced Dancers, Congress of International Society of Biomechanics - ISB 2011 Brussels, Brussels, Belgium, 2011.

[14] LotT M.B., Laws K.L., The Physics of Toppling and Regaining Balance during a Pirouette, J. Dance Med. Sci., 2012, 16 (4), 167-174, https://www.ncbi.nlm.nih.gov/pubmed/ 26731094

[15] O'Kane J.W., KADEL N., Anterior impingement syndrome in dancers, Curr. Rev. Musculoskelet. Med., 2008, 1 (1), 12-16, https://www.ncbi.nlm.nih.gov/pubmed/19468893

[16] Prochazkova M., Tepla L., Svoboda Z., Janura M., Cieslarova M., Analysis of foot load during ballet dancers' gait, Acta Bioeng. Biomech., 2014, 16 (2), 41-45, https:// www.ncbi.nlm.nih.gov/pubmed/25088458

[17] RASMUSSEN J., DAMSGAARD M., VOIGT M., Muscle recruitment by the min/max criterion - a comparative numerical study, J.
Biomech., 2001, 34 (3), 409-415, https://www.ncbi.nlm.nih.gov/ pubmed/11182135

[18] Sugano A., Laws K., Physical analysis as a foundation for pirouette training, Medical Problems of Performing Artists, 2002, 18, 29-32.

[19] Swain C., RedDing E., Trunk muscle endurance and low back pain in female dance students, J. Dance Med. Sci., 2014, 18 (2), 62-66, https://www.ncbi.nlm.nih.gov/pubmed/24844422

[20] TwitchetT E.A., Koutedakis Y., WyON M.A., Physiological fitness and professional classical ballet performance: a brief review, J. Strength Cond. Res., 2009, 23 (9), 2732-2740, https://www.ncbi.nlm.nih.gov/pubmed/19910802

[21] Vaganova A., Grundlagen des klassischen Tanzes (Basic principles of classical ballet), Henschel, Berlin, Germany, 2002.

[22] Werber B., Dance medicine of the foot and ankle: a review, Clin. Podiatr. Med. Surg., 2011, 28 (1), 137-154, https:// www.ncbi.nlm.nih.gov/pubmed/21276523

[23] Wiesler E.R., Hunter D.M., Martin D.F., CurL W.W., Hoen H., Ankle flexibility and injury patterns in dancers, Am. J. Sports Med., 1996, 24 (6), 754-757, https:// www.ncbi.nlm.nih.gov/pubmed/8947396

[24] Wyon M.A., Abt G., Redding E., Head A., Sharp N.C., Oxygen uptake during modern dance class, rehearsal, and performance, J. Strength Cond. Res., 2004, 18 (3), 646-649, https://www.ncbi.nlm.nih.gov/pubmed/15320648. 